\title{
Self-care competence of patients with an intestinal stoma in the preoperative phase
}

Competência para o autocuidado na fase pré-operatória da pessoa com estoma de eliminação intestinal

Competencia para el autocuidado en la fase preoperatoria de la persona con estoma de eliminación intestinal

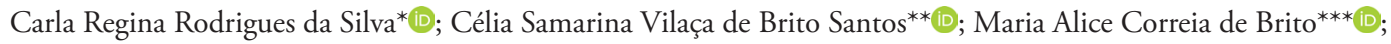
Teresa Maria Silva Cardoso****; Joana Rodrigues Lopes ${ }^{* * * * *}$

\section{Abstract}

Background: Patients undergoing intestinal stoma formation need to develop their stoma self-care competence. This competence should start being developed during the preoperative phase.

Objective: To identify patients' stoma self-care competence in the preoperative phase, particularly on the day before ostomy surgery.

Methodology: Quantitative, descriptive, and cross-sectional study. Non-probability sampling technique with 50 participants. Data were collected using the assessment form of the Self-Care Competence of the Person with an Intestinal Stoma (CAO-EI: ESEP).

Results: The level of knowledge represents the self-care competence of patients with an intestinal stoma in the preoperative phase of an ostomy surgery.

Conclusion: The multidimensional nature of the self-care competence of patients with intestinal stoma justifies exploring other domains of this competence besides knowledge in the preoperative phase given the identified benefits on the process of adaptation after surgery.

Keywords: self-care; ostomy; colostomy; ileostomy; nursing

\section{Resumo}

Enquadramento: A pessoa a quem será construída uma ostomia de eliminação intestinal necessita de desenvolver competência para o autocuidado ao estoma. $\mathrm{O}$ desenvolvimento dessa competência deve iniciar-se na fase pré-operatória.

Objetivo: Identificar a competência para o autocuidado ao estoma da pessoa na fase pré-operatória, especificamente no dia anterior à cirurgia com confeçấo de uma ostomia de eliminaçâo intestinal.

Metodologia: Estudo quantitativo, descritivo e transversal. Técnica de amostragem não probabilística com 50 participantes. O instrumento de recolha de dados foi o formulário de avaliação da Competência de Autocuidado da Pessoa com Ostomia de Eliminação Intestinal (CAO-EI: ESEP).

Resultados: $\mathrm{O}$ conhecimento representa a competência para o autocuidado ao estoma que a pessoa apresenta na fase pré-operatória de cirurgia com construção de uma ostomia de eliminação intestinal.

Conclusáo: A natureza multidimensional da competência para o autocuidado ao estoma de eliminaçáo intestinal justifica que outros domínios dessa competência, além do conhecimento, sejam trabalhados na fase pré-operatória, pelos conhecidos benefícios no processo de adaptação na fase posterior à cirurgia.

Palavras-chave: autocuidado; ostomia; colostomia; ileostomia; enfermagem

*MSc., Nurse Specialist in Medical-Surgical Nursing, Nursing School of Porto, $4200-072$ Porto, Portugal [enf_carlasilva@ @otmail.com].@ https://orcid.org/0000-0001-5147-2751 Contribution to the article: literature search, data collection, statistical treatment and evaluation, data analysis and discussion, and article writing. Address for correspondence: evaluation, data analysis and discussion, and article writing. Address for correspondence
Rua do Outrelo, n. 138, $4905-665$ Vila de Punhe - Viana do Castelo, Portugal.
**:Ph.D., Coordinating Professor, Nursing School of Porto, 4200-072. Porto, Portugal [ce*:Ph.D., Coordinating Professor, Nursing School of Porto, 4200-072, Porto, Portugal ce-

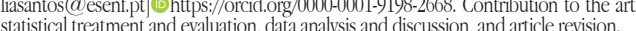
statistical treatment and evaluation, data analysis and discussion, and article revision.
$* * * \mathrm{Ph}$. Adjunct Professor. Nursing School of Porto, $4200-072$. Porto Port ***:Ph.D., Adjunct Professor, Nursing School of Porto, 4200-072, Porto, Portugal
[alice@esenf.pt].Dhttps://orcidorg/0000-0003-4414-4383. Contribution to the article: alice@esent.pt].O https://orcid.org/0000-0003-4414-4383. Contribution to the article: statistical treatment and evaluation, data analysis and discussion, and article revision.
$* * * *$ MSc. Nurse Specialist in Community Nursing Nursing School of Porto $4200-$ 072, Porto, Portugal [teresamcardoso@gmail.com]. Contribution to the article: data collection and article revision.

******MSc., Nurse Specialist in Medical-Surgical Nursing, Nursing School of Porto, 4200-072, Porto, Portugal [joanarolopes@gmail.com]. Contribution to the article: article revision.

\section{Resumen}

Marco contextual: La persona sometida a una ostomía de eliminación intestinal necesita desarrollar la competencia para el autocuidado del estoma. El desarrollo de esta competencia debe iniciarse en la fase preoperatoria.

Objetivo: Identificar la competencia de autocuidado del estoma de la persona en el período preoperatorio, en concreto, el día anterior a la operación para una ostomía de eliminación intestinal.

Metodología: Estudio cuantitativo, descriptivo y transversal. Técnica de muestreo no probabilística con 50 participantes. El instrumento de recogida de datos fue el formulario de evaluación de la Competencia de Autocuidado de la Persona con Ostomía de Eliminación Intestinal (CAO-EI: ESEP).

Resultados: El conocimiento representa la competencia para el autocuidado del estoma que la persona presenta en la fase previa a la operación para una ostomía de eliminación intestinal.

Conclusión: La naturaleza multidimensional de la competencia para el autocuidado del estoma de eliminación intestinal justifica que, en la fase preoperatoria, se trabajen otros ámbitos de esa competencia, además del conocimiento, debido a los conocidos beneficios en el proceso de adaptación en la fase posterior a la operación.

Palabras clave: autocuidado; ostomía; colostomía; ileostomía; enfermería 


\section{Introduction}

The process of adapting to life with an intestinal stoma is characterized by a phase of vulnerability due to the challenges related to self-care (Silva et al., 2017).

The nurse plays a key role throughout this process and is responsible for facilitating the development of the stoma self-care competence, which is essential for patients to manage the changes associated with this new reality. According to Silva, Cardoso, Gomes, Santos, and Brito (2016), the development of the intestinal stoma selfcare competence is a health need with a strong involvement of nursing care. Thus, the nurse should contact with the patient who will undergo stoma surgery as early as possible. This contact, preferably in the preoperative phase, promotes the establishment of an interpersonal relationship between the nurse and the person-family and the development of trust and respect to bolster the learning process (Pantaroto, 2015), as well as influence the process of recovery in the postoperative phase, the prevention of complications, and the adaptation to life with a stoma (Harilingam et al., 2015; Goldblatt et al., 2017; Repic \& Ivanovic, 2017; Zeigler \& Min, 2017).

It is important to identify the patients' level of stoma self-care competence in the preoperative phase so that nurses can better identify their needs and prescribe nursing interventions for meeting them. According to Silva et al. (2016, p. 22), "through the assessment of ostomy self-care skills, it is possible to identify the patients' needs and, therefore, adapt nursing interventions". It should be noted that patients' stoma self-care competence are in the preoperative phase should ideally be assessed on the day before the surgery to safeguard that, on the one hand, the patient has already attended a stomal therapy nursing consultation and, on the other hand, that he/she had already signed the surgical consent form.

The objective of this study is to identify patients' stoma self-care competence in the preoperative phase, particularly on the day before intestinal ostomy surgery.

\section{Background}

First, it is important to clarify the overall concept of competence and, then, evolve into the more specific concept of stoma self-care competence.

The demonstration of knowledge is not, in itself, a synonym of competence. That would be too restrictive because competence is far from being limited to the cognitive sphere. In addition to the cognitive sphere, competence incorporates the psychomotor and affective spheres (Bloom as cited in Metcalf, 1999). This means that a person who demonstrates competence will simultaneously demonstrate cognitive (knowledge), psychomotor (ability), and affective (attitude) skills in the same situation.

Taking into account the definition of the concept of competence, it is important to move toward the concept of stoma self-care competence. Silva et al. (2016, p. 22) explain that "through the assessment of ostomy self-care skills, it is possible to identify the patients' needs and, therefore, adapt nursing interventions". In a study carried out by the same authors with the purpose of building an instrument for assessing the stoma self-care competence of people with an intestinal stoma, the stoma self-care competence was assumed as a multidimensional concept. Six areas were defined for its characterization: knowledge, self-monitoring, interpretation, decision-making, execution, and negotiation and use of health resources (Silva et al., 2016). Thus, the assessment of stoma self-care implies the nurse's assessment of the above-mentioned domains because the patient can demonstrate stoma self-care skills in some areas and not in others.

The literature recommends that the education of patients undergoing stoma surgery, as well as of their family, should take place in the preoperative phase. According to Hoon, Sally, and Hong-Gu (2013), education must be at the center of all nursing interventions aimed at this population group.

Preoperative education is essential for the re-adaptation process of the person who will live with an intestinal stoma because it contributes to reducing anxiety and fear through the clarification of doubts. Prior to surgery, patients are often unaware of what is a stoma, the devices associated with the stoma, and the changes in their daily lives as a result of the ostomy. The teaching, education, and training for stoma self-care should begin in the preoperative phase, and nursing interventions should make patients more familiar with the intestinal stoma and 
the associated devices (Schwartz \& Sá, 2013). Moreover, it is recommended that stoma site marking be performed, the impact of the stoma on intimacy and sexuality of the person/partner be explored, and progressive relaxation muscle therapy be offered (Registered Nurses' Association of Ontario [RNAO], 2009).

In a systematic review on patient education interventions for colorectal cancer patients with a stoma, Faury, Koleck, Foucaud, M'Bailara, and Quintard (2017) concluded that education has a positive impact on some psychosocial and self-management skills, indicating that this area should be further explored. Studies on this topic focus on the importance of preoperative education, but none of them describes these patients' actual stoma self-care competence at this stage. It is imperative, therefore, that nurses know the level of competence or areas of stoma self-care competence of the patients undergoing stoma surgery in the preoperative phase. This knowledge will contribute to identifying patients' needs that need to be addressed in the preoperative phase, as well as identifying the aspects to be improved during the preoperative preparation of this population group.

\section{Research question}

What is the level of self-care competence of patients who will undergo colorectal surgery with intestinal stoma formation (temporary or permanent) on the day before the surgery in hospital settings?

\section{Methodology}

A descriptive study was conducted with a quantitative and cross-sectional approach.

Data were collected between April and July 2011 at inpatient surgery departments for both men and women from three hospitals in the north region of Portugal. These institutions were providing care to patients with colorectal cancer and had a preoperative stomal therapy nursing consultation.

Data were collected using the assessment form of the Self-Care Competence of the Person with an Intestinal Stoma (CAO-EI: ESEP; Silva et al., 2016), which allows assessing the six do- mains of competence through 45 outcome indicators. Thus, in the knowledge domain, the nine outcome indicators allow assessing the patient's information about the stoma and associated devices, as well as the resources available in the community in this area. In the self-monitoring domain, the seven outcome indicators allow assessing whether the patient is able to observe the stoma and monitor its characteristics, as well as those of the effluent, documenting significant occurrences. With regard to interpretation, four outcome indicators allow assessing whether the patient is able to interpret possible changes associated with the stoma and the effluent. In the decision-making domain, the four outcome indicators aim to assess whether the patient can take decisions about stoma self-care, identifying and recognizing those consequences. In the execution domain consisting of 17 outcome indicators, it is possible to assess whether the patient is able to perform the procedures related to stoma and peristomal skin care. The domain of negotiation and use of health resources is composed of four outcome indicators aimed to assess whether the patient is able to negotiate and use the resources available to stoma patients in a timely manner.

The researchers or nurses who had received training for that purpose assessed the domains of self-care stoma competence on an ordinal 3-point Likert scale to identify the level of stoma self-care competence demonstrated by the patients. The score ranged from 1 to 3 , in which the higher the score, the lower the competence demonstrated by the patient: 1 - fully demonstrates; 2 - partially demonstrates; and 3 - does not demonstrate (Silva et al., 2016).

The CAO-EI: ESEP form also allows characterizing the patient using attribute variables (for example: age; marital status; education level; profession; and professional situation), clinical variables (for example: clinical diagnosis; type of surgery; type and duration of the stoma), treatment variables (for example: stomal therapy nursing consultation in the preoperative phase and contact with patients with a stoma before surgery), and other variables, such as the existence of a caregiver in the family.

Of the population of patients proposed for colorectal surgery with probable intestinal stoma formation in three hospitals in the north of Portugal, the sample was composed of those who 
met the following inclusion criteria: inpatients proposed for elective colorectal surgery with possible intestinal stoma formation (permanent or temporary); with a signed informed consent form; aged 18 years or more and who agreed to participate in the study, after being duly clarified. Patients with cognitive and/or motor impairment that would prevent the learning process were excluded from the study. Whenever necessary, cognitive impairment was assessed using the Mini-Mental State Examination, which is validated and adapted to the Portuguese population (Guerreiro et al., 1994).

The study sample was collected by convenience sampling and consisted of 50 people who met the inclusion criteria. Table 1 shows the characterization of the study sample.

The participants' mean age was 61 years, rang- ing from 21 to 85 years. In this sample, $88 \%$ of the participants had schooling, of whom $71 \%$ had only completed the fourth grade; $60 \%$ were men; $86 \%$ were married or cohabiting; and $78 \%$ had a family caregiver (in $62 \%$ of the cases the caregiver was the spouse). All participants were scheduled for colorectal surgery with possible intestinal stoma formation and all of them were aware of the diagnosis underlying the need for surgery. A total of $78 \%$ of patients had the diagnosis of rectal cancer, $82 \%$ of them would undergo a colostomy, and $52 \%$ of them a temporary ostomy. The majority of participants (82\%) had never had prior contact with a patient with a stoma and $58 \%$ of them had attended stomal therapy nursing consultations. However, the stoma site had not been marked in half of the sampled participants in the preoperative phase.

Table 1

Sample characterization

\begin{tabular}{|c|c|c|c|c|c|}
\hline & IQR & Min. & Max. & $M$ & $S D$ \\
\hline Age & 64 & 21 & 85 & 60.9 & 15.0 \\
\hline Years of education & 15 & 2 & 17 & 5.9 & 4.0 \\
\hline Academic qualifications & & & & $n$ & $\%$ \\
\hline Does not know how to read or write & & & & 6 & 12.0 \\
\hline With schooling & & & & 44 & 88.0 \\
\hline Education level & & & & $n$ & $\%$ \\
\hline $4^{\text {th }}$ grade & & & & 31 & 70.5 \\
\hline $6^{\text {th }}$ grade & & & & 3 & 6.8 \\
\hline $9^{\text {th }}$ grade & & & & 5 & 11.4 \\
\hline Secondary education & & & & 1 & 2.3 \\
\hline Higher education & & & & 4 & 9.1 \\
\hline Gender & & & & $n$ & $\%$ \\
\hline Male & & & & 30 & 60.0 \\
\hline Female & & & & 20 & 40.0 \\
\hline Marital status & & & & $n$ & $\%$ \\
\hline Single & & & & 4 & 8.0 \\
\hline Married/Cohabiting & & & & 43 & 86.0 \\
\hline Widowed & & & & 3 & 6.0 \\
\hline Current professional situation & & & & $n$ & $\%$ \\
\hline Actively employed & & & & 8 & 16.0 \\
\hline Not actively employed (sick leave, leave) & & & & 9 & 18.0 \\
\hline Unemployed & & & & 2 & 4.0 \\
\hline Retired, pensioner or in reserve status & & & & 26 & 52.0 \\
\hline Houseworker & & & & 5 & 10.0 \\
\hline
\end{tabular}




\begin{tabular}{|c|c|c|}
\hline Current profession & $n$ & $\%$ \\
\hline Experts from intellectual and scientific professions & 4 & 23.5 \\
\hline Administrative staff and similar & 3 & 17.6 \\
\hline Service workers and shop and market sales workers & 3 & 17.6 \\
\hline Craft and related trade workers & 3 & 17.6 \\
\hline Plant and machinery operators and assemblers & 4 & 23.5 \\
\hline Informal caregiver & $n$ & $\%$ \\
\hline Yes & 39 & 78.0 \\
\hline No & 11 & 22.0 \\
\hline Informal caregiver & $n$ & $\%$ \\
\hline Spouse/ Partner & 24 & 61.6 \\
\hline Son/Daughter & 8 & 20.5 \\
\hline Father/ Mother & 1 & 2.6 \\
\hline Son-in-law/ Daughter-in-law & 2 & 5.1 \\
\hline Brother/ Sister & 2 & 5.1 \\
\hline Another relative/ Cohabitant & 2 & 5.1 \\
\hline Clinical diagnosis & $n$ & $\%$ \\
\hline Rectal cancer & 39 & 78.0 \\
\hline Colon cancer & 8 & 16.0 \\
\hline Inflammatory bowel disease & 3 & 6.0 \\
\hline Type of intestinal stoma & $n$ & $\%$ \\
\hline Colostomy & 41 & 82.0 \\
\hline Ileostomy & 9 & 18.0 \\
\hline Type of intestinal stoma, by duration & $n$ & $\%$ \\
\hline Temporary & 26 & 52.0 \\
\hline Permanent & 24 & 48.0 \\
\hline Contact with patients with a stoma before surgery & $n$ & $\%$ \\
\hline Yes & 9 & 18.0 \\
\hline No & 41 & 82.0 \\
\hline Attending stomal therapy nursing consultation & $n$ & $\%$ \\
\hline Yes & 29 & 58.0 \\
\hline No & 21 & 42.0 \\
\hline Stoma site marking & $n$ & $\%$ \\
\hline Yes & 25 & 50.0 \\
\hline No & 25 & 50.0 \\
\hline
\end{tabular}

Note. $\mathrm{IQR}=$ Interquartile range; Min. = Minimum; Max. = Maximum; $M=$ Mean; $S D=$ Standard deviation.

For descriptive data analysis, a database was created using IBM SPSS Statistics software, version 19.0 for Windows. For data treatment and analysis, the measures used in this study corresponded to sums of answers to items which were individually measured on an ordinal scale. By summing the results of the answers to the different items, it was assumed that these results were parts of a larger whole. It should be noted that the ascending order of the level in the form scale corresponds to the decreasing order of the level of demonstration of the indicator, which results from the fact that the assessment scale's scoring is reversed. This study met the ethical assumptions inherent to health research involving human 
beings. Authorization was obtained from the ethics committees of the health institutions involved in this study, with the identification codes N/REF 352/2011, 30.MAI11 09526, and $017 / \mathrm{CE} / \mathrm{SR}$. All participants were asked to give their informed consent for participation in the study. They were also ensured data confidentiality and the right to withdraw from the study at any moment without prejudice.

\section{Results}

The stoma self-care competence demonstrated by the participants in the preoperative phase was limited to the knowledge domain, which means that, on the day before surgery with intestinal stoma formation, no participant demonstrated no other domain of stoma self-care competence besides the knowledge domain (Table 2).

Participants who had already signed the informed consent for surgery were considered eligible to participate in the study; however, one of the participants $(2 \%)$ was not able to mention what was an intestinal stoma. Of the remaining participants, $60 \%(n=30)$ demonstrated partial knowledge and 38\% $(n=19)$ full knowledge.

With regard to the knowledge about the purpose of the stoma, the results were similar, with
$48 \%(n=24)$ of the participants knowing the purpose of the stoma, $48 \%(n=24)$ knowing partially, and $4 \%(n=2)$ not knowing at all.

The sampled participants were unaware of the stoma characteristics given that $96 \%(n=48)$ of them did not show any knowledge about this indicator. In the same way, in relation to the signs of stoma complications, only $4 \%(n=2)$ of participants were partially aware and 96\% $(n=48)$ of them were totally unaware.

Of the study participants, $38 \%(n=19)$ were unaware of stoma care devices and $62 \%(n=31)$ only knew some of them.

With regard to the frequency of changing the stoma bag or wafer/flange, the results showed that $48 \%(n=24)$ of the participants did not know when to change the bag and 52\% $(n=26)$ did not know when to change the wafer/flange. Moreover, $12 \%(n=6)$ of them knew when to change the bag, whereas only $4 \%(n=2)$ of them knew when to change the wafer/flange.

The majority of the sampled participants were unaware of the resources available to the patients with a stoma in the community. In this sample, $62 \%(n=31)$ of participants did not demonstrate knowledge about the existing resources, 36\% ( $n=18)$ demonstrated partially, and only one participant (2\%) demonstrated full knowledge.

All participants (100\%) recognized their needs in the domain of knowledge about stoma care.

Table 2

Sample distribution according to the assessment of each indicator of the domain of knowledge about the stoma self-care competence in the preoperative phase

\begin{tabular}{lcc}
\hline Indicators of the knowledge domain & $n$ & $\%$ \\
\hline Mentions what is an intestinal stoma & & \\
Fully demonstrates & 19 & 38.0 \\
Partially demonstrates & 30 & 60.0 \\
Does not demonstrate & 1 & 2.0 \\
Mentions the purpose of the intestinal stoma & & \\
Fully demonstrates & 24 & 48.0 \\
Partially demonstrates & 24 & 48.0 \\
Does not demonstrate & 2 & 4.0 \\
Mentions the characteristics of the intestinal stoma & & \\
Fully demonstrates & 0 & 0.0 \\
Partially demonstrates & 2 & 4.0 \\
Does not demonstrate & 48 & 96.0 \\
\hline
\end{tabular}




\begin{tabular}{|c|c|c|}
\hline \multicolumn{3}{|c|}{ Mentions the signs of intestinal stoma complications } \\
\hline Fully demonstrates & 0 & 0.0 \\
\hline Partially demonstrates & 2 & 4.0 \\
\hline Does not demonstrate & 48 & 96.0 \\
\hline \multicolumn{3}{|c|}{ Mentions stoma care devices } \\
\hline Fully demonstrates & 0 & 0.0 \\
\hline Partially demonstrates & 31 & 62.0 \\
\hline Does not demonstrate & 19 & 38.0 \\
\hline \multicolumn{3}{|c|}{ Mentions when to change the stoma bag } \\
\hline Fully demonstrates & 6 & 12.0 \\
\hline Partially demonstrates & 20 & 40.0 \\
\hline Does not demonstrate & 24 & 48.0 \\
\hline \multicolumn{3}{|c|}{ Mentions when to change the stoma wafer/flange } \\
\hline Fully demonstrates & 2 & 4.0 \\
\hline Partially demonstrates & 22 & 44.0 \\
\hline Does not demonstrate & 26 & 52.0 \\
\hline \multicolumn{3}{|c|}{ Mentions the community resources available to the patient with a stoma } \\
\hline Fully demonstrates & 1 & 2.0 \\
\hline Partially demonstrates & 18 & 36.0 \\
\hline Does not demonstrate & 31 & 62.0 \\
\hline \multicolumn{3}{|c|}{ Recognizes the needs in the domain of knowledge stoma care } \\
\hline Fully demonstrates & 50 & 100.0 \\
\hline Partially demonstrates & 0 & 0.0 \\
\hline Does not demonstrate & 0 & 0.0 \\
\hline
\end{tabular}

As regards the mean score for each indicator in the domain of knowledge about the stoma self-care competence (Table 3 ), the mean in the indicator on the recognition of the needs in the domain of knowledge about stoma care was $1.0(S D=0.00)$, followed by the mean scores in the domain of knowledge about the indicators "mentions the purpose of the intestinal stoma" and "mentions what is an intestinal stoma”, with a mean of $1.56(S D=0.58)$ and $1.64(S D=0.53)$, respectively. The lowest mean scores were found in the indicators about stoma characteristics and complications, each with a mean score of $2.96(S D=0.20)$. These mean scores are very close to the level of knowledge "does not demonstrate", represented by score 3 (a difference of 0.04).

The overall mean in the domain of knowledge about the stoma self-care competence was $2.22(S D=0.28)$.

Table 3

Interquartile range, mean, and SD by indicator and total score of the domain of knowledge about the stoma self-care competence in the preoperative phase

\begin{tabular}{lccc}
\hline Indicators of the knowledge domain & IQR & \multicolumn{2}{c}{$S D$} \\
\hline Mentions what is an intestinal stoma & 2 & 1.64 & 0.53 \\
Mentions the purpose of the intestinal stoma & 2 & 1.56 & 0.58 \\
Mentions the characteristics of the intestinal stoma & 1 & 2.96 & 0.20 \\
Mentions the signs of intestinal stoma complications & 1 & 2.96 & 0.20 \\
Mentions stoma care devices & 1 & 2.38 & 0.49 \\
\hline
\end{tabular}




\begin{tabular}{lccc}
\hline Mentions when to change the stoma bag & 2 & 2.36 & 0.69 \\
Mentions when to change the stoma wafer/flange & 2 & 2.48 & 0.58 \\
Mentions the community resources available to the patient with a stoma & 2 & 2.60 & 0.54 \\
Recognizes the needs in the domain of knowledge about the stoma & 0 & 1.00 & 0.00 \\
\hline Overall mean of the knowledge domain & 1.45 & 2.22 & 0.28 \\
\hline
\end{tabular}

Note. IQR = Interquartile range; $M=$ Mean; $S D=$ Standard deviation.

\section{Discussion}

These results are not in line with the expected stoma self-care competence in the preoperative phase which is found in the guidelines published in the literature on this matter. The results show that the stoma self-care competence demonstrated at this stage is limited to the domain of knowledge (cognitive sphere), although the literature highlights the importance of exploring the psychomotor (ability) and affective (attitude) skills of the stoma selfcare competence already in the preoperative phase. The results obtained in this study show that the patient who will undergo an intestinal stoma surgery only demonstrates (partial) knowledge in the preoperative phase rather than any of the other domains which characterize the stoma self-care competence. In view of the above, it can be said that the stoma selfcare competence in the preoperative phase is limited to the domain of knowledge.

In the domain of knowledge, and taking into account its indicators, it is possible to conclude that some of the participants recognize the objective of the stoma (its purpose) but do not know how to define/describe it (what it is). This result may reflect a greater concern with the stoma than with surgery, that is, the ostomy. Rust (2011) explains that there are people who are more afraid of living with a stoma than the surgery itself. These people's concern seems to gravitate around the stoma and not so much the surgery, which might be due to the fact that the stoma is the visible part of the surgery, the thing that is responsible for life with a bag and the reason for the changes in self-care and, consequently, in their daily lives.

The indicators related to the stoma characteristics and complication signs were clearly those with a lower level of demonstration of knowledge. Even though the patient still does not have a stoma in the preoperative phase, it is recommended that he/she becomes familiar with the reality of the stoma at this stage (RNAO, 2009; Slater, 2010). A person who is aware of the stoma characteristics and warning signs will be able to identify and notify possible changes as early as possible (RNAO, 2009).

The majority of participants are only partially aware of stoma care devices and nearly half of the sample is unaware of the frequency for changing the stoma bag and wafer/flange. These results also differ from what would be expected since it is recommended that patients become familiar with the stoma devices and receive information on its replacement frequency before the surgery. A common practice in the preoperative phase is having patients taking home a kit with the devices needed to care for the stoma (Slater, 2010). In addition, the results show that more than half of the sample is unaware of the resources available in the community to the person who lives with a stoma. These results are worrying because the access to stoma devices strongly influences the process of adaptation and acceptance of the patient with a stoma. Mota, Gomes, and Petuco (2016, p. 6) argue that this indicator facilitates life with a stoma, explaining that the essence of the life of a person with a stoma "is now being represented by the materiality of the stoma in their body, dependent on the stoma bag and accessories". The patient who will undergo stoma surgery reacts differently to the news, depending on their family, social, and cultural context. For some of them, the ostomy represents the disease, for others, it represents the possibility of cure or improved quality of life (Pantaroto, 2015). The process of acceptance and adaptation to the new reality is not clear-cut and depends on internal and external factors. However, some concerns are common to these patients, such as body changes, the fear 
of rejection, changes in intimacy, and the fear of stoma leaks in public or social situations (Carmel \& Scardillo, 2016; Zeigler \& Min, 2017). These concerns may be at the basis of every participant's recognition of the need to acquire knowledge about the new reality.

The literature points to several benefits of the preoperative preparation of patients who will undergo surgery for stoma formation. Given the increasingly shorter periods of postoperative hospital stay, the preoperative stomal therapy nursing consultation assumes special relevance because patients will have to rapidly develop the stoma self-care competence. Therefore, there must be a relationship between the patient-family and the nurse so that the knowledge required to perform the procedures can be assimilated and the teaching objectives attained: apprehension, assimilation, and reporting of the information conveyed; the ability of the patient/family to care for the stoma and replace associated devices; demonstration of device replacement; demonstration of independence in stoma self-care; and identification of the different procedures in case of peristomal complications and prevention of these complications (Lenza, Sonobe, Buetto, Santos, \& Lima, 2013).

An integrative review on nurses' educational interventions to patients undergoing intestinal stoma formation in the preoperative phase concluded that further studies are needed on nursing care delivery to this population group in the preoperative phase in order to systematize nurses' intervention within the multidisciplinary team (Schwartz \& Sá, 2013). There are few data available on the effect of educational interventions and the decrease in the length of hospital stay, readmissions, and stoma-associated complications (Forsmo et al., 2016). The few studies exploring the educational interventions for patients with a stoma had a common denominator: the preoperative consultation by a stomal therapy nurse and the marking of the stoma site before surgery but differed widely in other aspects. Similarly, the content of these interventions, as well as their duration are unknown (Phatak, Li, Karanjawala, Chang \& Kao, 2014). In this way, it is not possible to compare the results of different studies because the strategies, content, and time spent in the imple- mentation of the prescribed nursing interventions are different.

This study had some limitations. The small sample size is a limitation because it prevents the extrapolation and generalization of results. This study should be extended to a larger sample and data be collected at other health institutions besides those in the north of Portugal.

It would also be important to conduct a longitudinal study to apply the CAO-EI: ESEP form to the same patient at different stages throughout the process of adaptation to the new reality. In this way, it would be possible to assess and compare the patient's stoma selfcare competence from the preoperative phase until the community and, thus, plan the nursing care delivered to these patients based on the identified needs.

Although some studies mention the sociodemographic, clinical, and treatment variables which are capable of influencing the process of adaptation to life with a stoma, further studies are needed to explore the influence of these variables on the different outcome indicators of the six domains of the intestinal stoma self-care competence.

\section{Conclusion}

The development of the stoma self-care competence is characterized for being a cognitive, psychomotor, and affective learning process, and it is recommended that the patient develop knowledge, skills, and attitudes in the preoperative phase to manage the new care needs. However, the results of this study demonstrate that learning at this stage seems to be limited to the cognitive domain of competence - knowledge -, which has implications for both nursing practice and research. The results of this study raise questions which should be clarified in future studies. These questions relate to the effectiveness of the preoperative preparation of patients undergoing surgery for stoma formation, as well as to the nurse's assessment of the patient's availability to learn versus the amount of information provided.

The overall mean score in the domain of knowledge about stoma self-care competence 
showed that the participants' knowledge ranged from level 2 (partially demonstrates) to level 3 (does not demonstrate), being clear that participants demonstrate, on average, little knowledge. However, all of the study participants recognized that they require more knowledge about their new condition, which seems to add the issue of the patient's potential to develop the stoma self-care competence to the issue of availability.

Participants demonstrated a lower level of knowledge about the stoma characteristics and complication signs. Nurses need to provide more information about these topics during these patients' preoperative education. Given the multidimensional nature of the stoma self-care competence, it is important that other domains, besides knowledge, be explored during the preoperative phase, particularly given the known benefits in the process of adaptation to the new reality after surgery. Nonetheless, the results of this study seem to reveal some lack of consistency between the models exposed and the models being used for the development of the stoma self-care competence in the preoperative phase. The literature clearly supports the need for patients to develop several domains of this competence in the preoperative phase; however, it can be concluded that knowledge is patient's stoma self-care competence in the preoperative phase.

It is highly important to identify patients' stoma self-care competence in the preoperative phase because it allows planning nursing care delivery based on the identified needs of this population group.

\section{References}

Carmel, J. E., \& Scardillo, J. (2016). Rehabilitation Issues and Special Ostomy Patients Needs. In J. Carmel, J. Colwell \& M. Goldberg. Core Curriculum. Ostomy Management (chapter 13). Hong Kong, China: Wolters Kluwer \& Wound Ostomy and Continence Nurses Society, ISBN 978-1-4511-9439-5.

Faury, S., Koleck, M., Foucaud, J., M'Bailara, K., \& Quintard, B. (2017). Patient education interventions for colorectal cancer patients with stoma: A systematic review. Patient Education Counseling, 100(10), 18071819. doi: 10.1016/j.pec.2017.05.034.

Forsmo, H., Pfeffer, MD., Rasdal, A., Sintonen, H., Körner, H., \& Erichsen, C. (2016). Pre- and post- operative stoma education and guidance within an enhanced recovery after surgery (ERAS) programme reduce length of hospital stay in colorectal surgery. International Journal of Surgery, 121-126. doi: 10.1016/j. ijsu.2016.10.031.

Goldblatt, J., Buxey, K., Paul, E., Foot-Connolly, R., Leech, T., \& Bell, S. (2017). Study on the time taken for patients to achieve the ability to self-care their new stoma. ANZ Journal of Surgery, 1-4. doi: 10.1111/ ans. 14195 .

Guerreiro, M., Silva, A., Botelho, M., Leitão, O., Castro-Caldas, A., \& Garcia, C. (1994). Adaptação à população portuguesa da traduçáo do Mini Mental State Examination. Revista Portuguesa de Neurologia, 1(9), 9-10.

Harilingam, M., Sebastian, J., Twum-Barima, T., Boshnaq, M., Mangam, S., Khushal, A., Marzouk, D., \& Tsavellas, G. (2015). Patient-related factors influence the risk of developing intestinal stoma complications in early post-operative period. ANZ Journal of Surgery, 1-5. doi: 10.1111/ans.13397.

Hoon, L., Sally, C., \& Hong-Gu, H. (2013). Effect of psychosocial interventions on outcomes of patients with colorectal cancer: A review of the literature. $E$ uropean Journal of Oncology Nursing, 17, 883-891. doi: 10.1016/j.ejon.2013.05.001

Lenza, N., Sonobe, H., Buetto, L., Santos, M., \& Lima, M. (2013). The teaching of self-care to ostomy patients and their families: an integrative review. Revista Brasileira em Promoção da Saúde, 26(1), 149-145.

Metcalf, C. (1999). Stoma care: Empowering patients through teaching practical skills. British Journal of Nursing, 8(9), 583-600. doi: 10.12968/bjon.1999.8.9.6621.

Mota, M., Gomes, G., \& Petuco, V. (2016). Repercussôes no processo de viver da pessoa com estoma. Texto Contexto Enfermagem, 25(1), 1-8. doi: 10.1590/0104070720160001260014.

Pantaroto, H. (2015). O cuidado da pessoa nos períodos pré, trans e pós-operatório de cirurgia geradora de ostomia. In M. Paula, P. Paula \& I. Cesaretti (Eds.), Estomaterapia em Foco e o Cuidado Especializado (pp. 93-106). São Caetano do Sul, Brasil: Yendis Editora.

Phatak, R., Li, L., Karanjawala, B., Chang, G., \& Kao, L. (2014). systematic review of educational interventions for ostomates. Diseases of the Colon \& Rectum, 57(4), 529-537. doi: 10.1097/DRC.0000000000000044.

Registered Nurses' Association of Ontario. (2009). Ostomy care and management: Clinical best practice guidelines. Toronto, Canada: Author.

Repic, G., \& Ivanovic, S. (2017). Impact of the level of education on the quality of life of colostomy patients. Acta Medica Medianae, 56(1), 75-81. doi: 10.5633/ amm.2017.0112. 
Rust, J. (2011). Complications arising from poor stoma siting. Gastrointestinal Nursing, 9(5), 17-22. doi: 10.12968/gasn.2011.9.5.17.

Schwartz, M., \& Sá, S. (2013). Educational action of the nurse in preoperative of making stoma bowel: an integrative review. Revista de Enfermagem UFPE, 7 (esp), 6233-6239. doi: 10.5205/reuol.4397-36888-6-ED.0710esp201323

Silva, C., Cardoso, T., Gomes, A., Santos, C., \& Brito, M. (2016). Development of a self-care competence assessment form for the person with an intestinal stoma. Revista de Enfermagem Referência, 4(11), 21-30. doi:

\subsection{7/RIV16036.}

Silva, C., Sousa, F., Lima, J., Pinto, M., Brito, M., \& Cruz, I. (2017). Living with an ileostomy: a case study on the transition process. Revista de Enfermagem Referência, 4(14), 111-120. doi: 10.12707/RIV17015.

Slater, R. (2010). Managing quality of life in the older person with a stoma. British Journal of Community Nursing, 15(10), 480-484. doi: 10.12968/ bjen.2010.15.10.78728

Zeigler, M., \& Min, A. (2017). Ostomy management: Nuts and bolts for every nurse's toolbox. Learn the facts about ostomy care. American Nurse Today, 12(9), 6-11. 
